Rev. Biol. Neotrop. 9(2): 14-23. 2012

\title{
L PARAQUAT AFECTA LA ACTIVIdAd de LA ATPASA MITOCONDRIAL, LAS CONCENTRACIONES DE GLUTATIÓN Y LA EXPRESIÓN DE LA GP-GLICOPROTEÍNA EN EL HÍGADO DEL PEZ COLOSSOMA MACROPOMUM
}

\author{
Aridays Oliveros \\ Postgrado de Biología aplicada, laboratorio de proteínas e inmnotoxicidad, Núcleo de Su- \\ cre, UDO. Venezuela.
}

\section{Evelin Rojas-Villarroel}

Centro de investigación ciencia y tecnología de los alimentos, laboratorio de bioquímica, facultad de ciencias veterinarias, LUZ, Maracaibo, estado Zulia. Venezuela.

\section{Raquel Salazar-Lugo}

Postgrado de Biología aplicada, laboratorio de proteínas e inmnotoxicidad, Núcleo de Sucre, UDO. Venezuela. Departamento de Bioanalisis, Escuela de Ciencias, UDO, Venezuela. E-mail: raquelugove@yahoo.com

\begin{abstract}
Resumo: Avaliou-se o efeito de uma concentração subletal de $10 \mathrm{mg} / \mathrm{L}$ de o herbicida paraquat sobre a actividade ATPase mitocondrial (ATPasamit), a concentração de glutationa (GSH) e a expressão de P-glicoproteina (P-gp) de fígado de peixe Cachama, Colossoma macropomum , 54 juvenis foram expostos para os dias 7, 14 e 21. Após os ensaios, determinou-se a atividade de ATPase, a concentração de glutationa paraquat, e eletroforese de proteínas de membrana para visualizar fração P-gp. Os resultados demonstram que o paraquat e diminui a actividade da ATPasamit concentração de GSH em 14 dias de exposição PQ. Observou-se a expressão de uma proteína de 170 kDa aparentes massa molecular correspondente com a P-gp, que foi observada enriquecido 7 e 21 dias de exposição. No fígado, a concentração de herbicida foi mantido entre 0,34 e 1,59 $\pm 1,68 \pm 0,32 \mathrm{mg} / \mathrm{GPQ}$ durante o tempo de exposição. Paraquat afectado a fosforilação potencial de membrana mitocondrial e oxidação, tal como demonstrado pela inibição da actividade da ATPasamit; décimo quarto dia de exposição para os peixes é crítica, uma vez que inibe a ATPasamit, diminui a concentração de glutationa e de expressão da P-gp glicoproteína.
\end{abstract}

Palavras-Chave: Colossoma, glutationa, paraquat, GP-glicoproteínas.

Abstract: We evaluated the effect of sublethal concentration of $10 \mathrm{mg} / \mathrm{L}$ of the herbicide paraquat on mitochondrial ATPase activity (ATPasamit), glutathione concentration (GSH) and the expression of P-glycoprotein (P-gp) in liver of the fish cachama, Colossoma macropomum, 54 juveniles were exposed for 7, 14 and 21 days. After the assays, we determined the ATPase activity, glutathione concentration, paraquat and electrophoresis membrane fraction proteins to visualize P-gp. The results demonstrate that paraquat decreases ATPasamit activity and GSH concentration at 14 days of PQ exposure. It was observed the expression of a protein of apparent $170 \mathrm{kDa}$ molecular mass corresponding with the P-gp, which was observed enriched 7 and 21 days of exposure. In liver, the concentration of herbicide was maintained between 0.34 and $1.59 \pm 1.68 \pm 0.32 \mathrm{mg} / \mathrm{GPQ}$ during the exposure time. Paraquat affected the mitochondrial membrane potential and oxidative phosphorylation, as demonstrated by inhibition of the activity of the ATPasamit; the fourteenth day of exposure to the fish is critical, since it inhibits ATPasamit, decreases the concentration of glutathione and expression of P-gp glycoprotein.

KeY Words: Colossoma, glutathione, paraquat, GP-glicoproteins. 


\section{INTRODUCCIÓN}

E. paraquat (PQ; 1-1' dimetil 4-4' bipiridilo dicloride) es considerado como el tercer herbicida más usado extensivamente a nivel mundial (Cha et al., 2012). Este es un herbicida de amplio espectro, de contacto post emergente, reconocido por emplearse en el control de semillas terrestres y acuáticas, como desecante y defoliador de hierbas, no volátil e insoluble en grasas (Sáenz et al., 1997). En Venezuela, el herbicida se emplea ya sea solo o principalmente mezclado con otros herbicidas para el control de malezas anuales y perennes, en las plantaciones de plátanos, cacao, yuca, maíz (García y Medina 2005; Girón y Alfonzo, 2000).

El ciclo redox del PQ es el mecanismo principal para producir daños oxidativos en muchos tipos celulares (Black et al., 2008). Este ciclo ocurre cuando el dicatión $\mathrm{PQ}^{2+}$, en solución acuosa activado por radiólisis, reacciona rápidamente con el oxígeno molecular produciendo el anión

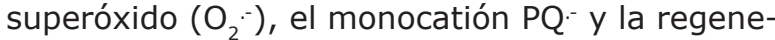
ración del dicatión (Boetslerli, 2007). En la célula eucariota, la mitocondria es uno de los organelos afectados rápidamente por el efecto del metabolismo del PQ debido a la producción de radicales libres (Castello et al., 2007). Hirai et al. (1992) demostraron que el PQ altera la ultraestructura de las mitocondrias en ratas, ellos observaron, mayores alteraciones mitocondriales en los hepatocitos que en las células pulmonales; por su parte, Parvaez y Raisuddin (2006) señalaron que en organismos no blancos, entre ellos peces, se encuentran alteraciones mitocondriales a nivel de las células de riñones, hígado y branquias.

Se ha reportado un aumento de la actividad de la superóxido dismutasa en el hígado de tilapias expuestas a $0,5 \mathrm{mg} \cdot \mathrm{L}^{-1}$ de $\mathrm{PQ}$ durante cuarenta y cinco días (Figueredo-Fernandes, et al., 2006); una disminución significativa de los niveles del glutatión reducido en el hígado y branquias ha sido observada en el pez Channa punctata expuesto a 1 ppm de PQ durante 24 horas (Parvaez y Raisuddin, 2006). Igualmente, el PQ induce inmunotoxicidad en el pez C. macropomum expuesto a dosis subletales de este herbicida durante 28 días y daños histológicos en branquias, hígado y riñón; la magnitud del efecto del PQ sobre el pez dependió de la temperatura de exposición (Salazar-Lugo et al., 2009; 2011).

Así mismo, la célula es capaz de protegerse activando otros mecanismos de defensa que aminoren el estrés oxidativo generado por la presencia del tóxico, entre ellos, se encuentra el metabolismo de xenobióticos fase I, II y III. En la fase III, se menciona la sobreexpresión de la glicoproteína-P, gp-P, razón por la cual muchos peces pueden ser capaces de adaptarse a vivir $y$ reproducirse en aguas contaminadas (Kurelec et al., 1992). La gp-P una proteína transmembrana, de $170 \mathrm{KDa}$ de masa molecular, perteneciente a la familia de proteínas transportadoras de la clase ABC, casette dependientes de ATP, (Ferté, 2000); es la expresión de una de los sistemas de defensa conservado evolutivamente, el sistema de resistencia multixenobióticos, MXR, (Albertus y Laine, 2001).

La significativa expresión de la gp-P homóloga en teleósteos, en el tejido hepático del pez Fundulus heteroclitus y en el pez intermareal Anoplarchus purpurescens indica que esta proteína puede ser la primera línea de defensa en la desintoxicación, de este pez y que la actividad de este transportador es sensible a concentraciones bajas y variantes de tóxicos indicando que la gp-P tiene un potencial importante como biomarcador en ambientes estresores (Bard et al., 2002).

Debido a que el $\mathrm{PQ}$ pasa a los cuerpos de aguas naturales, mediante la lluvia, donde es acumulado por diferentes organismos esto sugiere que los peces son susceptibles a la contaminación por el herbicida y pudiese ser tomado en cuenta como un factor a considerar en las evaluaciones de organismos en cauces cercanos a zonas agrícolas (Procitropicos, 1996). En este trabajo se plantea evaluar el efecto de la concentración subletal del herbicida paraquat sobre la actividad ATPasa, y de glutatión en el tejido hepático del pez Colossoma macropomum (Cuvier, 1818); mejor conocido por su nombre vulgar:cachama, especie de importancia en acuicultura y pesquerías dulceacuícolas; distribuida en Venezuela en los ríos: Guanare, Portuguesa, Meta, Apure, Carora y Orinoco zona donde se desarrolla actividad agrícola (Machado, 1982).

\section{Metodología}

\section{OBTENCiÓN y MANTENIMIENTO DE LOS PECES}

Se utilizaron juveniles de C. macropomum (Cuvier, 1818) con índices biométricos de 17,87 $\pm 7,88 \mathrm{~cm}$ y $87,69 \pm 34,23 \mathrm{~g}$, los peces fueron suministrados por la Piscícola ALMA C.A. (Campo Mata, estado Anzoátegui) y trasladados en bolsas con agua aireada hasta el Laboratorio de Camarones Dulceacuícola, Departamento de Biología, Universidad de Oriente Núcleo Sucre, donde fueron aclimatados durante un mes.

\section{EXPOSICIÓN A 10 MG.L-1 DE PQ}

La dosis subletal de $10 \mathrm{mg} / \mathrm{L}$ fue escogida a partir de la $\mathrm{LC}_{50} 96 \mathrm{H}$ determinada para este organismo por Salazar-Lugo et al., (2009) y fue de $48 \mathrm{mg} . \mathrm{L}^{-1}$. Un grupo de 54 peces fueron expuesto a la concentración subletal de PQ $\left(10 \mathrm{mg}^{-\mathrm{L}^{-1}}\right)$, durante 7,14 , y 21 días y otro grupo de 54 peces fue utilizado como control. Para cada tratamiento a ensayar, se realizaron tres replicas, se colocaron seis peces de talla similar en acuarios con 
$55 \mathrm{~L}$ de agua desclorinada y aireada continuamente, una temperatura de $29,78 \pm 0,46^{\circ} \mathrm{C}, \mathrm{pH}$ : $7,70 \pm 0,25^{\circ} \mathrm{C}$, oxígeno $3,8 \mathrm{mg} \cdot \mathrm{L}^{-1}$, dureza 106 ppm. Estos parámetros físicos-químicos fueron monitoreados diariamente. La temperatura, $\mathrm{pH}$ y oxígeno fueron registrados con el uso de termómetro (YSI modelo 30), pHmetro (Hanna modelo HI9025.) y oxigenómetro (YSI modelo 55), respectivamente. La dureza del agua fue medida con el Kit marca Lamotte. El agua fue recambiada diariamente reponiendo la concentración subletal del herbicida, en los organismos expuestos. Los peces fueron alimentados diariamente con cachamarina $25 \%$ proteína de PURINA ${ }^{\circledR}$, a razón del $40 \%$ de su peso total.

\section{AISLAMIENTO DE LA FRACCIÓN MITOCONDRIAL}

Una vez concluido el tiempo de exposición, los peces fueron adormecidos en agua fría y disectados para obtener el hígado. Para el aislamiento de la fracción mitocondrial del hígado, se aplicó el método de centrifugación diferencial en sacarosa, según Saz y Lascure (1969): 0,5 $\mathrm{g}$ de tejido fueron cortados y homogenizados en medio mitocondrial: 0,24M Sacarosa, 0,005mM ácido etilendiamino tetraacético (EDTA) y 0,15\% Albumina de Suero Bovino (BSA), pH 7,4). El homogenizado fue centrifugado a $4^{\circ} \mathrm{C}$ en centrífuga Hettich 32R a $100 \mathrm{~g}$ durante 10 minutos; filtrado a través de lana de vidrio y el filtrado fue centrifugado a $7800 \mathrm{~g}$ durante 30 minutos a $4{ }^{\circ} \mathrm{C}$. Luego, el precipitado fue resuspendido en $10 \mathrm{ml}$ de medio mitocondrial y centrifugado de nuevo a $7800 \mathrm{~g}$ durante $30 \mathrm{~min}$. a $4^{\circ} \mathrm{C}$. Los sedimentos marrones que contenían la fracción mitocondrial fueron guardados bajo congelación a $-20^{\circ} \mathrm{C}$, hasta su uso.

PREPARACIÓN DE PARTÍCULAS SUBMITOCONDRIALES (PSM)

La fracción mitocondrial se resuspendió en una solución amortiguadora que contenía $10 \mathrm{mM}$ Tris/ $\mathrm{HCl}$; 0,25M sacarosa; $5 \mathrm{mM} \mathrm{NaCl}$; $\mathrm{pH} \mathrm{7,6;} \mathrm{se}$ sonicó 3 veces en frío a 6 watts y una amplitud de 30 durante 15 segundos con intervalos de enfriamiento de 1 minuto, en un sonicador Cole Palmer modelo CP130. La solución sonicada fue centrifugada a $8700 \mathrm{~g}$ durante 120 minutos en centrífuga Hettich $32 \mathrm{R}$ a $4^{\circ} \mathrm{C}$. Los precipitados que contenían las PSM, fueron resuspendidos y empleados para la determinación de la actividad ATPasa. La proteína soluble de la suspensión de PSM se determinó mediante el método de Bradford (1976) utilizando BSA (Sigma) como proteína estándar para preparar una curva de calibración $(0-20 \mathrm{mg} / \mathrm{ml})$.

\section{Determinación de LA ACTIVIDAd ATPASA}

La actividad ATPasa de la suspensión de PSM fue determinada en la fase de velocidad máxima; para ello se preparó una mezcla de reacción, la cual contenía 1,5 M Tris/ $\mathrm{HCl} \mathrm{pH} 7.6 ; 3 \mathrm{mM} \mathrm{MgCl}$; 3mM Adenosin Trifosfato (ATP) y suspensión de PSM (volumen final de la reacción: 1,1 ml completados con agua deionizada). Esta mezcla se incubó a $37^{\circ} \mathrm{C}$ durante 15 minutos, la reacción fue detenida por adición de 0,1 mL de ácido tricloroacético (TCA) $50 \%$. La proteína precipitada se eliminó por centrifugación a $2700 \mathrm{~g}$ durante 5 minutos.

Por cada muestra de PSM se incluyó un tubo control y uno experimental; a la mezcla de reacción de los tubos controles se le agregó 0,1 ml de TCA $50 \%$ antes de agregar el ATP esto con la finalidad de eliminar la interferencia por fósforo endógeno. Para cuantificar la cantidad de fósforo inorgánico liberado por la acción enzimática de la ATPasa mitocondrial de los tejidos estudiados se aplicó el método de Fiscke-Subbarow (1925). Se tomó $1 \mathrm{ml}$ del sobrenadante de la mezcla de reacción y se le agregó $1,75 \mathrm{~mL}$ de agua destilada, $250 \mu \mathrm{L}$ de Reactivo 1 (molibdato de amonio $2,5 \%$ en $5 \mathrm{~N}$ de $\mathrm{H}_{2} \mathrm{SO}_{4}$ ) y $125 \mu \mathrm{L}$ del reactivo ANSA (metabisulfito de sodio15\%; ácido aminonaftol sulfónico $0,25 \%$ y sulfito de sodio $1 \%$ ). Se mezcló e incubó durante $10 \mathrm{~min}$ a $37^{\circ} \mathrm{C}$ y se midió la absorbancia a $680 \mathrm{~nm}$ en espectrofotómetro Smart Spec 3000/ BioRAD a 680 nm de longitud de onda Para determinar la concentración de Pi liberado por la actividad enzimática de la ATPasa mitocondrial, se elaboró una curva de calibración de $\mathrm{Pi}(0-20 \mu \mathrm{mol})$, usando una solución madre de $\mathrm{KH}_{2} \mathrm{PO}_{4} 2 \mathrm{mM}$.

\section{Determinación de GLutatión Reducido (GSH)}

La determinación de la concentración de GSH fue llevada a cabo de acuerdo a la metodología de Beutler et al. (1963). Se homogeneizaron 0,2 g de tejido hepático en $1 \mathrm{~mL}$ de Tris $\mathrm{HCl} 20 \mathrm{mmol} / \mathrm{L}$ a $\mathrm{pH} 8$; se centrifugaron a $4000 \mathrm{~g}$ durante 15 minutos a $4^{\circ} \mathrm{C}$. Luego se mezclaron $0,2 \mathrm{ml}$ del sobrenadante obtenido, con 0,9 mL de agua destilada, se adicionó $1,5 \mathrm{~mL}$ de solución precipitante $(1,67 \mathrm{~g}$ de ácido metafosfórico glacial (mezcla de $\mathrm{HPO}_{3}$ y $\mathrm{NaPO}_{3}$ ); 0,2 gr de EDTA y $30 \mathrm{~g}$ de NACl en $100 \mathrm{~mL}$ de agua destilada), se centrifugó a $4000 \mathrm{~g}$ durante 10 minutos a $4^{\circ} \mathrm{C}$ y se dejo en reposo por 5 minutos. Posteriormente a $0,25 \mathrm{~mL}$ del sobrenadante se le añadió $1 \mathrm{~mL}$ de reactivo DTNB (5,5' dithiodis 2-ácido nitrobenzoico) y se midió la absorbancia a una longitud de onda de $412 \mathrm{~nm}$, en un espectronic 21D, Milton Roy. La curva de calibración $(10-50 \mu \mathrm{g} / \mathrm{mL}$ GSH) se realizó a partir de una solución patrón 0,1 mmol/L de GSH. La concentración de GSH fue expresada en $\mathrm{nmol} / \mathrm{mg}$ de proteínas.

\section{Determinación de Paraquat (PQ)}

La concentración de PQ fue determinada en el tejido hepático de los peces mediante una adap- 
tación del método descrito por la OAC norma No 969.09 (1969) y Dinis-Oliveira et al. (2006). Para ello, 0,5 g de tejido hepático fueron homogeneizados en $5 \mathrm{~mL}$ de buffer $\mathrm{KH}_{2} \mathrm{PO}_{4 /} \mathrm{Na}_{2} \mathrm{HPO}_{4} 50 \mathrm{mM}$, $\mathrm{pH} 7,4$ y $0,1 \%$ TritonX, la mezcla fue agitada $\mathrm{y}$ centrifugada a $3000 \mathrm{~g}$ a $4^{\circ} \mathrm{C}$ por 15 minutos. Tres mililitros del sobrenadante fueron tomados para añadirle ácido 5-sulfosalicílico (5\% como concentración final) y centrifugado a $13000 \mathrm{~g}$ a $4^{\circ} \mathrm{C}$ por 10 minutos. Seguidamente $2 \mathrm{~mL}$ del sobrenadante se alcalinizaron con $\mathrm{NaOH} 10 \mathrm{~N}$ hasta que el $\mathrm{pH}$ estuviera entre 9,5 y 10,0 ; luego se mezclaron suavemente por inversión con cristales de Ditionito de Sodio ( $0,1 \%$ como concentración final). Inmediatamente fue leída la absorbancia en un espectrofotómetro UV/VIS Perkin Elmer lambda 25, a una longitud de onda de $600 \mathrm{~nm}$. Para determinar la concentración de $P Q$ se elaboró una curva de calibración utilizando una solución madre de 0,25 mg/ml de PQ preparada a partir de PQ 98\% de pureza (Metilviologen, 1,1'-dimetil-4,4'-bipyridylium dicloride; $\mathrm{C}_{12} \mathrm{H}_{14} \mathrm{Cl}_{2} \mathrm{~N}_{2}$; Sigma-Aldrich) la cual se diluyó hasta $0,05 \mathrm{mg} / \mathrm{mL}$ y se obtuvieron estándares de 0 a $10 \mu \mathrm{g} / \mathrm{mL} \mathrm{PQ}$.

\section{EXTRACCIÓN DE LA GLICOPROTEÍNA-P (GP-P)}

La extracción de la gp-P en las muestras de tejido hepático de los organismos estudiados, se realizó a partir del procedimiento descrito por Laine et al., (1991). Se tomó aproximadamente $0,15 \mathrm{~g}$ del hígado de $C$. macropomum y se le añadió $3 \mathrm{~mL}$ de buffer lisis: $10 \mathrm{mmol} / \mathrm{L}$ Piperazina $\mathrm{N}^{\prime} \mathrm{N}$ 'bis etano sulfónico (Pipes), 100mmol/L $\mathrm{KCl}$, $3 \mathrm{mmol} / \mathrm{L} \mathrm{NaCl}, 3,5 \mathrm{mmol} / \mathrm{L}$ y $1 \mathrm{mmol}$, acido etilenglicol tetraacético (EGTA) y un cóctel de inhibidor de proteasas (SIGMA) a pH 7,2. Esta mezcla se homogeneizó y la suspensión resultante fue centrifugada a $800 \mathrm{~g}$ a $4^{\circ} \mathrm{C}$, se tomó el sobrenadante para centrifugarlo nuevamente a $38000 \mathrm{~g}$ durante 30 minutos a $4^{\circ} \mathrm{C}$. El precipitado se resuspendió nuevamente en $3 \mathrm{~mL}$ de buffer lisis que contenía dodecil sulfato de Sodio (SDS) 5\%, se incubó por dos horas en frío y se centrifugó a $10000 \mathrm{~g}$ durante 20 minutos a $4^{\circ} \mathrm{C}$, se removió el material insoluble. La concentración de proteínas fue determinada mediante el método de Bradford (1976).

\section{ELECTROFORESIS EN GELES DE POLIACRILAMIDA CON SDS (SDS-PAGE)}

Se tomaron de 25 a $30 \mu \mathrm{g}$ de proteína, de las preparaciones de la gp-P obtenidas de las diferentes muestras de hígado y $5 \mu \mathrm{L}$ de un marcador de masa molecular de proteínas de alto rango preteñido (BioRad), y fueron resueltos por electroforesis unidimensional en un gel de policriamida a $7 \%$ con SDS $1 \%$ en buffer Tris-glicina bajo condiciones reductoras (Albertus y Laine, 2001), corrida a 120 v durante 1hora aproximadamente.

Los geles, fueron teñidos mediante la tinción de plata, para ello fueron sometidos a agitación constante y suave en diferentes soluciones de la forma siguiente: toda la noche en una solución de Isopropanol, Ácido Acético y agua (25:7:68); al día siguiente se sumergieron en la solución fijadora de Metanol, Ácido Acético y agua (50:10:40) durante 30 minutos; seguidamente se colocaron en solución desteñidora Ácido Acético, Metanol, agua (7:5:88) durante 1 hora; luego fueron sumergidos en una solución de glutaraldehido $10 \%$ por 30 minutos, lavados durante 2 horas en agua deionizada; se cubrieron durante 15 minutos con una solución amoniacal $\mathrm{AgNO}_{3}$; fueron transferidos a otro envase plástico y fueron lavados 5 veces con agua deionizada, durante 1 minuto por cada lavado; se agregó la solución reveladora,; se transfirió el gel a la solución de mantenimiento (Ácido Acético 1\%), y fue escaneado para el registro permanente. La masa molecular aparente de la gp-P se obtuvo al graficar, el logaritmo de base 10 de la masa molecular conocida, de cada una de las proteínas del marcador de peso molecular versus la distancia recorrida por la misma.

\section{AnÁLISIS ESTADÍSTICOS}

Los datos obtenidos para la actividad ATPasa mitocondrial no cumplieron con los supuestos de homogeneidad y normalidad; por ello, se aplicaron para su análisis, pruebas estadísticas no paramétricas. Para realizar comparaciones de tres medianas, se usó un Kruskal-Wallis (KW); como análisis a posteriori y comparación de dos medianas, se aplicó el estadístico de Mann Whitney (MW). Para el glutatión los datos cumplieron con los supuestos de homogeneidad y normalidad; por ello se aplicaron pruebas estadísticas paramétricas; para comparaciones de dos promedios se realizó la prueba del t-student (Stell y James, 1980). En las pruebas estadísticas aplicadas se usaron seis peces como número muestral.

\section{Resultados}

\section{Actividad ATPasa}

La actividad ATPasa mitocondrial hepática (ATPasaMH) de los peces expuestos al herbicida, presentó una disminución no significativa en los siete días de exposición; mientras que, para los catorce y veintiún días se hallaron diferencias estadísticamente significativas a (MW $=60,5$ $p<0,001 ; \quad \mathrm{W}=50 ; \quad p<0,001$, respectivamente) (Figura 1). 


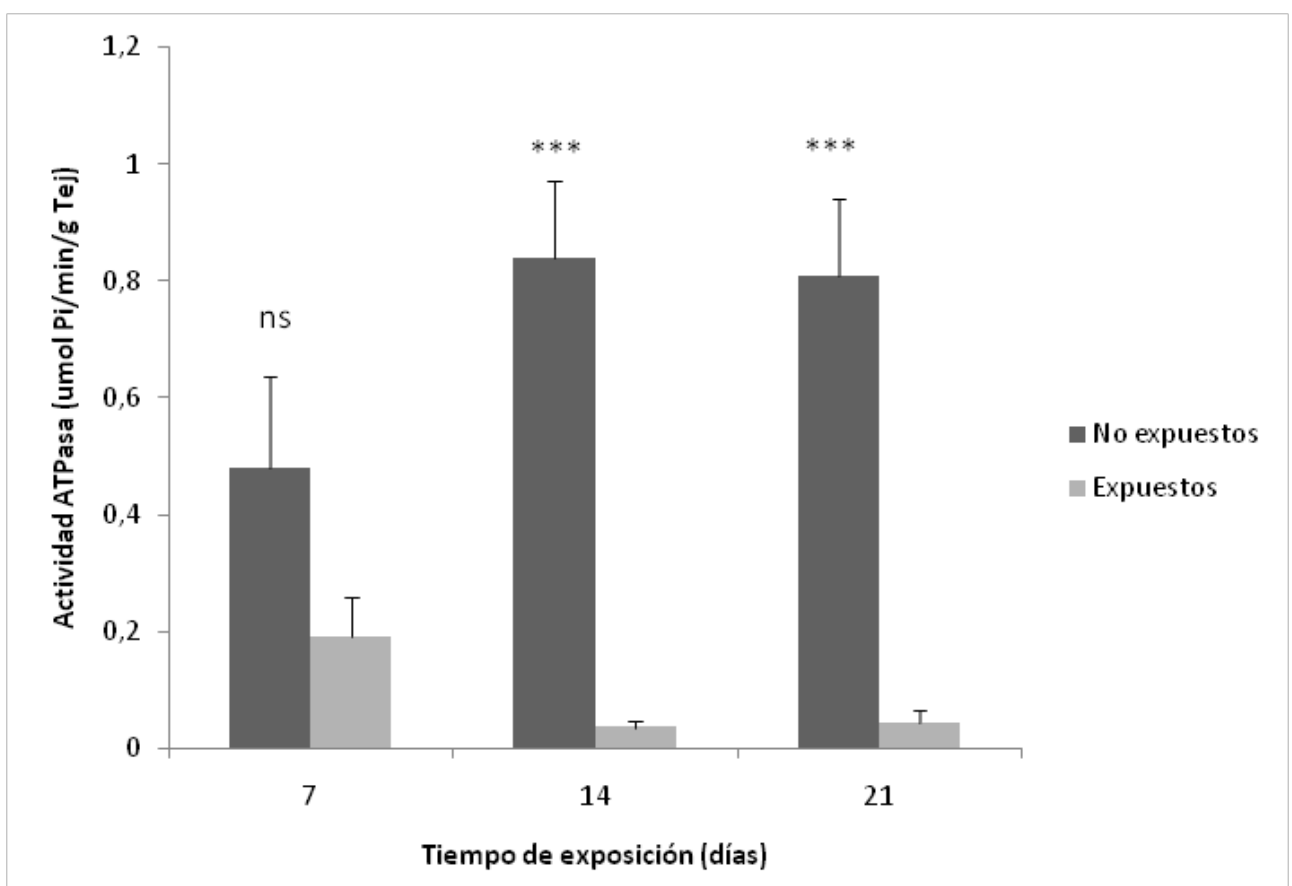

Figura 1. Actividad de la ATPasa mitocondrial hepática de C. macropomum no expuesta y expuesta a $10 \mathrm{mgr} . \mathrm{L}^{-1} \mathrm{PQ}$ a $29^{\circ} \mathrm{C}$ durante siete, catorce y veintiún días. $\mathrm{ns}=\mathrm{p}>0,05 ; * * *=\mathrm{p}<0,001 ; \mathrm{n}=6$.

\section{GlutATIÓN REDUCido (GSH)}

Los peces expuestos $\mathrm{PQ}$ siete días presentaron un aumento significativo $(t=4,7606 ; p<0,01)$ de la concentración de GSH en el tejido hepático con respecto a los peces no expuestos sin embargo se observa que para los catorce días de exposición esta concentración disminuye significativamente $(t=-4,8227 ; p<0,001)$, para nuevamente aumentar significativamente $(t=3,0935 ; \mathrm{p}<0,05)$ para los veintiún días (Figura 2 ). Estos hallazgos indican que el sistema redox de los hepatocitos presenta una activación durante los siete días de exposición, luego un agotamiento durante los catorce días y al final se evidencia una recuperación del mismo, por lo que se puede asumir una recuperación del sistema oxido-reductor de los peces expuestos al herbicida.

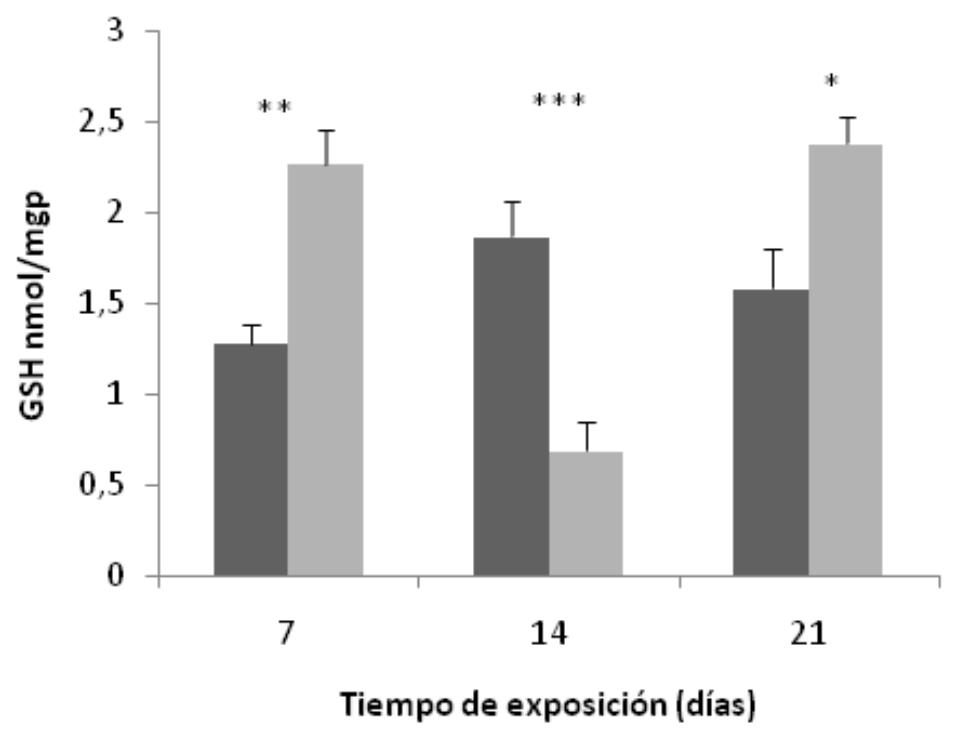

No expuestos

Expuestos

Figura 2. Concentración de GSH reducido hepático de C. macropomum no expuesto y expuesta a $10 \mathrm{mg} \cdot \mathrm{L}^{-1} \mathrm{PQ}$ a $29^{\circ} \mathrm{C}$ durante siete, catorce y veintiún días. $*=p<0,05, * *=p<0,01 ; * * *=p<0,001 ; n=6$. 
Paraquat (PQ)

Las concentraciones de paraquat en el hígado son similares en los tres tiempos de exposición al herbicida sugiriendo que en el tejido se han activado mecanismos de desintoxicación que impiden que se siga concentrando el tóxico en este tejido (Tabla 1 ).

Tabla 1. Concentración de PQ presente en el tejido hepático de C. macropomum expuesta a $10 \mathrm{mg} \cdot \mathrm{L}^{-1} \mathrm{PQ}$ a 29 ${ }^{\circ} \mathrm{C}$ durante siete, catorce y veintiún días.

\begin{tabular}{ccc}
\hline $\begin{array}{c}\text { Tiempo } \\
\text { Exposición } \\
\text { (días) }\end{array}$ & $\boldsymbol{\mu g} / \mathbf{m L}$ de $\mathbf{P Q} *$ & Desv. Est. \\
\hline 7 & 1,68469 & 0,34596 \\
14 & 1,68612 & 0,43040 \\
21 & 1,59789 & 0,32682 \\
\hline
\end{tabular}

*los $\mu \mathrm{g} / \mathrm{mL}$ representan la cantidad de PQ por g de tejido húmedo.

\section{EXPRESIÓN DE LA GP-GLICOPROTEÍNA}

La corrida electroforética realizada a la fracción de membrana de los hepatocitos de $C$ macropomum expuestos al herbicida PQ muestra el enriquecimiento de una banda de proteína con una masa molecular de aproximadamente 170 kDa observándose mayormente expresada en las fracciones de siete y de veintiún días de exposición lo que concuerda con el aumento de la concentración de GSH en el tejido hepático para este tiempo de exposición (Figura 3).

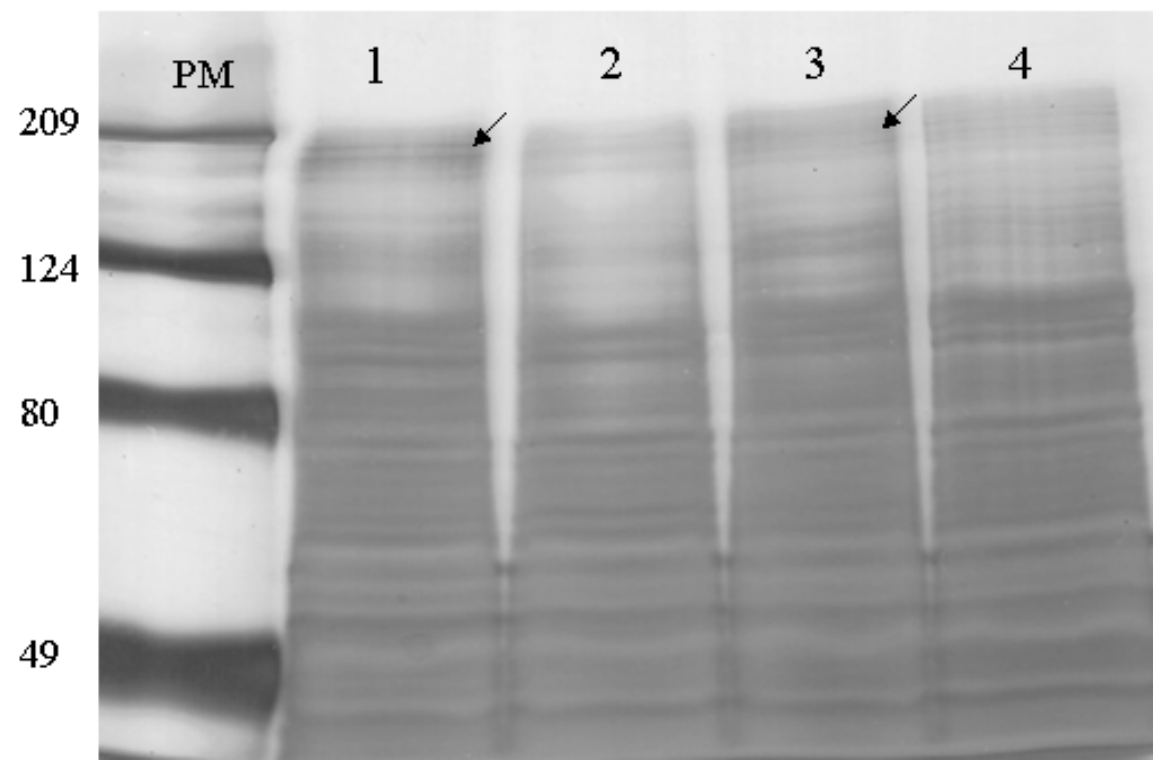

Figura 3. Eletroforesis de la fracción de membrana que contiene la gp-P provenientes de los hepatocitos de $C$. macropomum expuesta a $10 \mathrm{mg} \cdot \mathrm{L}^{-1} \mathrm{PQ}$ a $29^{\circ} \mathrm{C}$. PM: marcador de peso molecular, los números a la derecha indican la masa molelcular en kDalton. 1: siete días de exposición; 2: catorce días de exposición; 3: veintiún días de exposición; 4: no expuesto. La flecha señala la banda de peso molecular 170 kDa.

\section{Discusión}

La disminución de la actividad enzimática de la ATPasa mitocondrial hepática, de los peces expuestos al $\mathrm{PQ}$, sugiere la alteración bioenergética mitocondrial por la interacción con el tóxico. Esta alteración energética es producida una vez que el dicatión $\mathrm{PQ}^{2+}$ tiene contacto con la mitocondria para ser reducido vía enzimática, principalmente la oxido reductasa ubiquinona $\mathrm{NADH}$, Complejo $\mathrm{I}$, para formar el monocatión radical (PQ-) que reacciona rápidamente con el oxígeno $\left(\mathrm{O}_{2}\right)$ para producir el anión superóxido $\left(\mathrm{O}_{2}{ }^{-}\right)$y regenerar el $\mathrm{PQ}^{2+}$ (Cochemé y Murphy, 2008).

Las reacciones cíclicas de oxido reducción del $\mathrm{PQ}$ con algunos elementos del metabolismo oxidativo, como el citocromo $\mathrm{P}_{450}$ y la cadena transportadora de electrones genera especies reacti- 
vas de oxígeno (ROS): el peróxido de hidrógeno $\left(\mathrm{H}_{2} \mathrm{O}_{2}\right)$ y el radical oxidrilo $\left(\mathrm{OH}^{-}\right)$(Jing-Fen et al., 2006); compuestos que pudieron haberse generado en el tejido hepático de los peces expuestos en este estudio, causando la disminución de la actividad ATPasa debido a la posible peroxidación lípidica que producen los mismos en la membranas mitocondriales. Esto ha sido demostrado en mitocondrias de hepatocitos del pez Sparus aurata, expuesto a $50 \mathrm{mg} / \mathrm{Kg}$ de PQ (Pedrajas, 1995) y en mitocondrias de pulmones de ratas expuestas a $10 \mathrm{mM}$ de PQ (Palmeira 1995).

Sin embargo, Palmeira et al, (1995) contrario de los resultados obtenidos en esta investigación, reportan la estimulación de la ATPasa mitocondrial y la inhibición del complejo III de la cadena transportadora de electrones en mitocondrias de hepatocitos de ratas expuestas a PQ; y sostienen que este desacoplamiento entre la fosforilación oxidativa y la cadena transportadora de electrones se debe a la ligera permeabilización de la membrana mitocondrial interna al paso de $\mathrm{H}^{+}$, relativo a la peroxidación lipídica causada por el herbicida.

La diferencia entre los resultados de esta investigación y los de Palmiera op cit en relación a la actividad de la ATPasa mitocondrial pudiese ser explicado por las condiciones de este experimento y el desarrollado por ellos. En este trabajo, los organismos fueron expuestos a una dosis subletal de $P Q$ durante 21 días después de esto, se analizó la actividad mitocondrial de las células del hígado; Ellos utilizaron mitocondrias aisladas de hígado de ratas y las expusieron directamente durante 10 minutos al PQ. Posiblemente, la entrada directa del herbicida a la mitocondria (en el experimento de Palmeira op cit) logra estimular la fosforilación oxidativa debido a la capacidad oxido reductora del PQ que permite un aumento en el potencial de membranas, atribuido al aumento en el gradiente de protones transmembrana que estimulan la síntesis de ATP; este efecto puede ser observado durante ese corto periodo de tiempo; no obstante, la exposición del organismo completo por un tiempo prolongado al PQ quizás permite que este compuesto se acumule y magnifique el daño en la mitocondria puesto que esa misma capacidad oxidoreductora del PQ produce ROS que pueden generar la desorganización y el deterioro de la membrana mitocondrial interna originando que el potencial de protones disminuya y afectando la actividad ATPasa tal, como se observó en este estudio.

Los hallazgos de este estudio corroboran las evidencias que señalan que el $P Q$ produce un efecto tóxico sobre el metabolismo energético mitocondrial caracterizado por el desacoplamiento entre el transporte de electrones y la fosforilación oxidativa; lo que sugiere que el daño oxidativo del herbicida sobre la actividad ATPasa de las mitocondrias de hígado de C. macropomum es directo y no selectivo al desacoplar la síntesis de ATP del transporte de electrones; observación soportada por la presencia del herbicida en este tejido y la pérdida de la citoarquitectura normal de los hepatocitos de estos peces reportada por Salazar Lugo et al (2011).

El efecto oxidativo del PQ en C. macropomum también se evidenció por la disminución en las concentraciones de GSH reducido a los catorce días de exposición; representando este descenso un $68 \%$ en relación a los organismos no expuestos. Estos hallazgos son similares a los obtenidos por Parvaez y Raisuddin, (2006) quienes encontraron la disminución en la concentración de GSH reducido en diferentes tejidos del pez de agua dulce Channa punctata, expuesto a $1,0 \mathrm{mg}^{* \mathrm{~L}^{-1}}$ $\mathrm{PQ}$ durante 24 horas, reportando el mayor efecto tóxico del PQ sobre las branquias, seguido el hígado y por último los riñones; sugiriendo que la toxicidad inducida por el PQ fue tejido específica y depende del rol fisiológico de cada órgano.

La disminución del GSH total fue reportada por Farmen et al., (2010) en hepatocitos de trucha arcoíris expuesta a diferentes dosis de paraquat, con aumento de glutatión oxidado. Dukic et al., (2012) señalan que la oxidación de GSH es probablemente la principal forma como el $\mathrm{PQ}$ reduce las defensas antioxidantes provocando daño oxidativo EL GSH juega un papel central en el sistema antioxidante de la célula considerándose como un importante biomarcador de estrés oxidativo causado por contaminantes (Song et al., 2006).

Sin embargo, C. macropomum parece ser capaz de activar otras respuestas que pudiesen contribuir a disminuir el efecto del tóxico; una de estas es la inducción en la expresión de la gp-P, que se observó como una banda de aproximadamente $170 \mathrm{kDa}$; masa molecular que concuerda con la detección inmunoquímica realizada en fracciones de membranas provenientes de hígado, riñones, branquias, cerebro e intestino de los peces Anoplarchus purpurescens (Bard et al.; 2002) y Fundulus heteroclitus (Albertus \& Laine, 2001) expuestos a contaminantes ambientales y toxinas quimioterapéuticas, respectivamente. La inducción de la gp-P ha sido reportada en otros organismos tanto en líneas celulares expuestas a paraquat y se ha encontrado que la síntesis de la gp-P disminuye el efecto tóxico del herbicida (Dinis-Oliveira et al., 2006: 2008; Zerin et al., 2012).

Por otro lado, los resultados sugieren que el período de 14 días es el punto crítico de la exposición para los juveniles de C. macropomum ya que para ese período las condiciones antioxidantes del pez disminuyen como lo indica la disminución de la actividad ATPasa, de las concentraciones de GSH y de la expresión de la gp-P. Sin embargo, es importante señalar que aunque la actividad ATPasa mitocondrial hepática permaneció inhibida durante la exposición; la concentración de GSH aumentó y la banda de 170 KDa que representa la gp-P se enriqueció a los 21 días de exposición lo que sugiere que el organismo 
logra recuperar sus defensas antioxidantes, además, de esto se conoce que la $\mathrm{LC}_{50}$ a $96 \mathrm{~h}$ (48 $\mathrm{mg} . \mathrm{L}^{-1}$ ) para la especie es elevada en relación a lo reportado para otras especies (Extornet, 1996) por lo que es posible que los peces logran activar otros mecanismos compensatorios que le permiten tolerar la exposición prolongada a $\mathrm{PQ}$.

Estos resultados evidenciaron que el $P Q$ en una dosis de $10 \mathrm{mg} \cdot \mathrm{L}^{-1}$ es capaz de inducir cambios bioquímicos en juveniles de $C$. macropomum. Principalmente, disminuye la actividad ATPasa mitocondrial lo que se atribuye mayormente al estrés oxidativo, pero los peces logran restablecer su maquinaria bioquímica antioxidante para lograr su supervivencia durante la exposición prolongada como lo demuestra el aumento en las concentraciones de glutatión y la expresión de la gp-glicoproteina.

\section{Agradecimientos}

Este trabajo fue financiado por el Fondo $\mathrm{Na}$ cional de Ciencias Tecnología e Innovación proyecto UDO-FONACIT G2005000775, agradecemos a la piscicultora ALMA C.A. por suministrar los peces usados en el estudio.

\section{Referencias}

Albertus, J. y R.Laine. 2001. Enhanced xenobiotic trnasporter expresión in normal teleost hepatocytes: to enviromenal and chemotherapeutic toxins. The J. Exp. Biology. 204: 217-227.

Bard, S.; Woodin, B. y J Stegeman. 2002. Expression of P-glycoprotein and cytochrome P450 1A in intertidial fish (Anoplarchus purpurescens) exposed to environmental contaminants. Aquat. Toxicol. 60:17-32.

Beutler E.; Duron, O. y B. Mikus. 1963. Improved method for the determination of blood glutathione. The Journal of Laboratory and Clinical Medicine, 61: 882-888.

Black A.; Gray J.; Shakarjian M. y D Laskin. 2008. Increased oxidative stress and antioxidant expression in mouse keratinocytes following exposure to paraquat. Toxicol.. Applied Pharmacol. 231: 384-392.

Boetslerli, A. 2007. Mechanistic Toxicology.: Cellular transport and selective accumulation of potentially toxic xenobiotics \& Xenobiotic-induced oxidative stress: cell injury, signa- ling and gene regulation. Segunda edición. CRS Press. Taylor \& Francis group. 39-61p; 117-171p.

Bradford, M. 1976. A rapid and sensitive method for the quantitation of microgram quantities of protein utilizing the principle of proteindye binding. Anal. Biochem. 72: 248-254.

Castello, P.; Dreschel, D. y M Patel. 2007. Mitochondria are mayor source of paraquat-induced reactive oxygen species production in the brain. J. Biol. Chem.282 (19):1418614193.

Cochemé, H. y M. Murphy. 2008. Complex is the major site of mitocondrial superoxide production by paraquat. J. Biol. Chem. 283(4): 1786-1798.

Cha, ES;. Lee, YK.; Moon, EK.; Kim, YB.; Lee, YJ.; Jeong, WC.; Cho, EY.; Lee, IJ.; Hur, J.; Ha, M.; y WJ. Lee. 2012. Paraquat application and respiratory health effects among South Korean farmer.Occup Environ Med. 69(6):398-403

Dinis-Oliveira, R.; Remião, F.; Duarte, J.; Ferreira, R.; Sánchez Navarro, B. y F Carvalho. 2006. P-glycoprotein induction: an antidotal pathway for paraquat-induced lung toxicity. Free Radical Biol. Med.41:12131224.

Dinis-Oliveira, RJ.; Sánchez-Navarro, A.; Remião, F.; . Bastos ML.; y F. Carvalho. 2008. Paraquat poisonings: mechanisms of lung toxicity, clinical features, and treatment. Crit Rev Toxicol.38(1):13-71.

Djukic, MM.; MD. Jovanovic, M. Ninkovic, I. Stevanovic, K. Ilic, M. Curcic y J. Vekic. 2012. Protective role of $\mathbf{g l u t a t h i o n e ~ r e d u c t a - ~}$ se in paraquat induced neurotoxicity. Chem Biol Interact. 18 jun. En prensa.

Extoxnet.1996. Paraquat. 12 de marzo 2004. http://www.extoxnet.orst.edu/pips/paraquat.html

Farmen E, Olsvik PA, Berntssen MH, Hylland K, Tollefsen KE. 2010. Oxidative stress 
responses in rainbow trout (Oncorhynchus mykiss) hepatocytes exposed to pro-oxidants and a complex environmental sample. Comp Biochem Physiol C Toxicol Pharmacol.; 151(4):431-8.

Ferté, J. 2000. Analysis of the tangled relation between P-glycoprotein mediated multidrug resistence and the lipid phase of the cell membrane. Eur. J. Biochem. 267: 277-294.

Figueiredo-Fernandes, A.; Fontaínhas-Fernandes, A.; Peixoto, F.; Rocha, E. y M. Reis-Henriques. 2006. Effects of gender and temperature on oxidative stress enzymes in Nile tilapia Oreochromis niloticus exposed to paraquat. Pesticide Biochem. Physiol. 85(2): 97-103.

Fiske, C. y Y. Subbarow. 1925. The colorimetric determination of phosphorous. J. Biol. Chem. 66. (2): 375-400.

García P. y J Mejía. 2005 Control químico de malezas en maíz en un sistema de siembra directa. Agronomía Trop. 55(3): 363-380.

Girón C. y E. Alfonzo. 2000. Manejo integrado de malezas en yuca, estado Miranda. Agronomía Tropical 50(1):31-40.

Hirai, K.; Ikeda K. y G. Wang. 1992. Paraquat damage of rat liver mitochondria by superoxide production depends on extramitochondrial NADH. Toxicol. 72(1):1-16.

Jing-Fen, H.; Shou-Lin, W.; Xiao-Yang, H.; Chun-Yong, L. y H Jun-Yan. 2006. Effect of Genetic Variation on Human Cytochrome P450 Reductase-Mediated Paraquat Cytotoxicity. Toxicolg. Sciences 91(1):42-48.

Kurelec, B. 1992. The resistance multixenobiotic mechanism in aquatic organisms. Crit. Rev. Toxicol. 22: 23-43.

Laine,R.; Laipis, P.; Shay, N. \& Killberg, M. 1991. Identification of amino acid-regulated mRNA from rat liver as the mammalian equivalent of bacterial ribosomal protein L22. J. Biol. Chem. 266: 16969-16972.
Machado-Allinson, A. 1982. Estudio sobre la sistemática de la subfamilia Serrasalminae (Teleostei, Characidae). Parte I. Estudio comparado de los juveniles de las cachamas de Venezuela (genero: Colossoma y Piaractus). Acta Biol. Ven. 11(3):1-102.

OAC No 969.09. 1968. Paraquat in pesticide formulations. Spectrophotometric method. JAOAC. 51:1304-1306.

Palmeira, C.; Moreno, A. y V. Madeira. 1995. Mitochondrial bioenergetics is affected by the herbicide paraquat. Biochimica et Biophysica Acta.1229:187-192.

Parvez, S. y S. Raisuddin. 2006. Effects of paraquat on the freshwater fish Channa punctata (Bloch): Non-Enzymatic antioxidants as biomarkers of exposure. Arch. Environ. Contam. Toxicol. 50:392-397.

Pedrajas, J.; Peinado, J. y J. López-Barea. 1995. Oxidative stress in fish exposed to model xenobiotics. Oxidatively modified forms de $\mathrm{Cu}, \mathrm{Zn}$-superoxide dismutase as potencial biomarkers. Chemico-Biological Interactions. 98(3):267-282.

Procitropicos. Programa corporativo de investigación y transferencia de tecnología para los trópicos suramericanos. 1996. Propuesta de proyecto multinacional de investigación y desarrollo agropecuario. 13 de febrero 2004. <http ://www. procitropicos.org.br/pdf/Granos.pdf. $>$

Salazar-Lugo, R.; Estrella A.; Oliveros A, Rojas-Villarroel, E.; Villalobos de BL, M. Lemus. 2009. Paraquat and temperature affect nonspecific immune response of Colossoma macropomum. Environ. Toxicol. Pharmacol. 27 321-326.

Salazar-Lugo, R.; Mata, C.; Oliveros, A.; Rojas, L.; Lemus, M.; E Rojas-Villarroel. 2011. Histopathological changes in gill, liver and kidney of neotropical fish Colossoma macropomum exposed to paraquat at different temperature. Environmental toxicology and pharmacology 31: 490-495. 
Saz, H. y O. Lascure. 1969. The functions of phosphoenol pyruvate carboxykinase and malic enzyme in the anaerobic formation of succinate by Ascaris lumbricoides. Comp. Biochem. Physiol. 30(1): 49-60.

Sáenz, M.; Alberdi, J.; Di Marzio D.; Accorinti, J. y M. Tortorelli. 1997. Paraquat toxicity to different green algae. Bull. Environ. Contam. Toxicol. 58: 992-928.

Song, S. B.; Y. Xu, y B. S. Zhou. 2006. Effects of hexachlorobenzene on antioxidant status of liver and brain of common carp (Cyprinus carpio). Chemosphere 65: 699-706.
Stell, R. y H. James. 1980. Principles and procedures of statistics. Segunda edición. McGraw-Hill, New York.

Zerin T.; Kim, SY.; Hong S.; y HY. Song. 2012. Protective effect of methylprednisolone on paraquat-induced A549 cell cytotoxicity via induction of efflux transporter, P-glycoprotein expression. Toxicol Lett. 208(2):101-7.

Recebido em 24.XI.2012 Aceito em 20.III.2013 